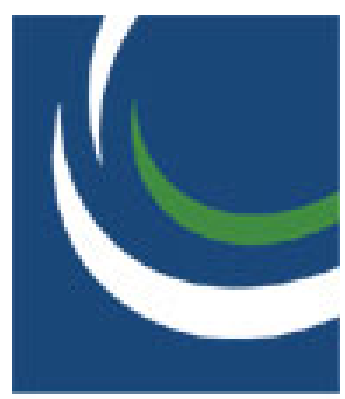

apsa

Government Partisanship, Labor Organization, and Macroeconomic Performance: A Corrigendum

Author(s): Nathaniel Beck, Jonathan N. Katz, R. Michael Alvarez, Geoffrey Garrett and Peter Lange

Source: The American Political Science Review, Vol. 87, No. 4 (Dec., 1993), pp. 943-948

Published by: American Political Science Association

Stable URL: http://www.jstor.org/stable/2938825

Accessed: $17 / 03 / 201417: 38$

Your use of the JSTOR archive indicates your acceptance of the Terms \& Conditions of Use, available at http://www.jstor.org/page/info/about/policies/terms.jsp

JSTOR is a not-for-profit service that helps scholars, researchers, and students discover, use, and build upon a wide range of content in a trusted digital archive. We use information technology and tools to increase productivity and facilitate new forms of scholarship. For more information about JSTOR, please contact support@ jstor.org.

American Political Science Association is collaborating with JSTOR to digitize, preserve and extend access to The American Political Science Review. 


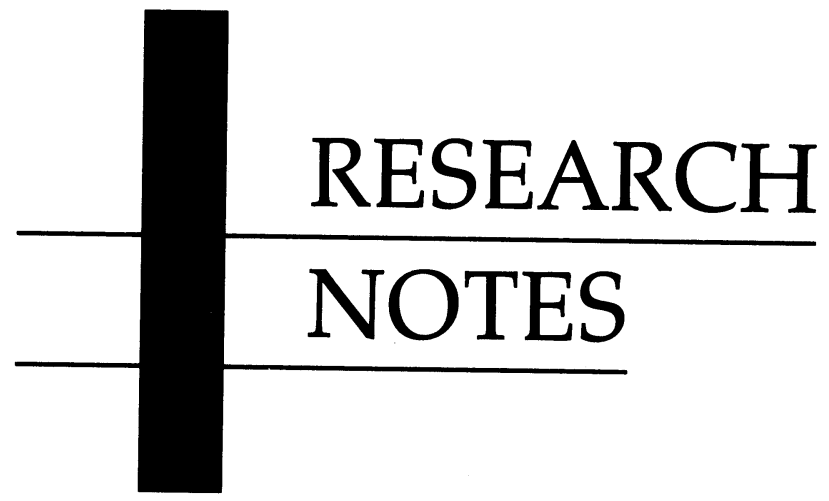




\title{
GOVERNMENT PARTISANSHIP, LABOR ORGANIZATION, AND MACROECONOMIC PERFORMANCE: A CORRIGENDUM
}

\author{
NATHANIEL BECK and JONATHAN N. KATZ University of Califormia, San Diego \\ R. MICHAEL ALVAREZ California Institute of Technology \\ GEOFFREY GARRETT Stanford University \\ PETER LANGE Duke University
}

\begin{abstract}
$A$
lvarez, Garrett and Lange (1991) used cross-national panel data on the Organization for Economic Coordination and Development nations to show that countries with left governments and encompassing labor movements enjoyed superior economic performance. Here we show that the standard errors reported in that article are incorrect. Reestimation of the model using ordinary least squares and robust standard errors upholds the major finding of Alvarez, Garrett and Lange, regarding the political and institutional causes of economic growth but leaves the findings for unemployment and inflation open to question. We show that the model used by Alvarez, Garrett and Lange, feasible generalized least squares, cannot produce standard errors when the number of countries analyzed exceeds the length of the time period under analysis. Also, we argue that ordinary least squares with robust standard errors is superior to feasible generalized least squares for typical cross-national panel studies.
\end{abstract}

I n a study of cross-validation using a model and data from Alvarez, Garrett and Lange (1991) (hereinafter AGL), Beck and Katz (1992) revealed a problem with the earlier statistical analysis. The problem is that limited data makes the procedure used by AGL (particularly for the standard errors) incorrect. ${ }^{1}$ Here we present a new method that allows for the computation of the basic AGL model, including standard errors. We find that the major conclusion of AGL-concerning the political and organizational determinants of economic growth-still holds but their conclusions regarding similar determinants of inflation and unemployment are open to question. Given the problems involved in the AGL analysis and the growing use of panel data in the study of comparative politics (e.g., Blais, Blake, and Dion 1993; Hicks and Swank 1992; Swank 1992), we feel it is important to discuss some methodological issues in the analysis of cross-national panel data.

AGL estimated a model relating political and labor organization variables (and some economic controls) to economic growth, unemployment, and inflation (building on Lange and Garrett 1985). The argument was that economic performance in advanced industrial societies was superior when labor was both encompassing and had political power or when labor was weak both in politics and in the market. A mismatch of labor's organizational and political strength, on the other hand, led to inferior economic performance. AGL estimated a model where economic performance was determined by

\section{$E($ Economic Performance $)=$}

$$
\beta_{0}+\beta_{1} \text { LORG }+\beta_{2} \text { LFCAB }+\beta_{3} \text { LORG } \times \text { LFCAB }
$$

$$
\begin{aligned}
& +\gamma \text { Vulnerability to the International Economy } \\
& +\rho \text { Lagged Economic Performance }+\varepsilon
\end{aligned}
$$

They undertook separate analyses for three measures of economic performance: the growth of gross domestic product, the change in unemployment, and the change in the rate of inflation. ${ }^{2}$ The independent variables of most interest are labor organizational strength (LORG, a time-invariant multiplicative index of the density and centralization of trade unions) and percentage of left-held cabinet positions (LFCAB) as a measure of labor political strength. The value of $\beta_{3}$, which measures the interactive impact of LORG and LFCAB on economic performance, provides the critical test of AGL's theory. The economic controls-vulnerability to the international economy-are world economic performance measures reflecting the openness of Organization for Economic Coordination and Development (OECD) economies; the lagged performance variable reflects the dynamic nature of the model. ${ }^{3}$

AGL used panel (time series cross-section) data to estimate equation 1 , with data for 16 OECD nations over the period 1970-84, producing 15 complete observations per country. ${ }^{4}$ We specified the variancecovariance matrix of the "error" process using a model of Parks (1967) as discussed by Kmenta (1986, 622-25). This model allowed for errors to be (1) serially correlated (in AGL this is country-specific), (2) heteroscedastic (country-specific and time-independent), and (3) contemporaneously correlated (across countries).

The Parks method uses feasible generalized least squares (FGLS) for dealing with this error process. This requires estimating the covariance matrix of the 
country errors and then transforming the data to remove this covariance. However, the estimated covariance matrix is singular if, as in AGL, the number of time points $(\mathrm{T})$ is less than the number of crosssectional units $(\mathrm{N})$ in the panel. This singularity makes application of feasible generalized least squares impossible.

To see the problem with the Parks method, assume that the data present no serial correlation. Let $t$ subscripts refer to years, running from 1 to $\mathrm{T}$; let $\mathrm{i}$ and j subscripts refer to countries, running from 1 to $N$. Let $\boldsymbol{\Omega}$ be the time-independent contemporaneous covariance matrix of the errors, with $\omega_{i j}$ the contemporaneous correlation for countries $i$ and $j$ and with $\omega_{i i}$ being country-specific but time-independent, heteroscedasticity. We assume the data is ordered so that the first $\mathrm{N}$ data points refer to the countries at time 1 and so forth. The variance-covariance matrix for all observations is then $\boldsymbol{\Omega} \otimes \mathbf{I}_{\mathbf{T}}$, where $\otimes$ is the Kronecker product and $\mathbf{I}_{\mathbf{T}}$ is a $\mathrm{T} \times \mathrm{T}$ identity matrix. $\boldsymbol{\Omega}$ is estimated using the residuals from an ordinary least squares (OLS) estimation of equation 1, that is,

$$
\hat{\omega}_{i j}=\frac{\Sigma_{t=1}^{T} e_{i t} e_{j t}}{T} .
$$

If $\mathbf{E}$ is the $\mathrm{T} \times \mathrm{N}$ matrix of residuals, then

$$
\hat{\mathbf{\Omega}}=\frac{\mathbf{E}^{\prime} \mathbf{E}}{T} \text {. }
$$

That this matrix be nonsingular is required by FGLS. Unfortunately, $\hat{\mathbf{\Omega}}$ is singular if $T<N$. $^{5}$

Here we offer a simpler technique than that used by AGL, which yields consistent (but inefficient) estimates of the coefficients of equation 1 . Most important, however, it yields consistent estimates of the standard errors, which allows us to draw inferences about the coefficient estimates.

Let us assume that whatever serial correlation exists is constant across countries. The Parks model, on the other hand, allows for the errors to show country-specific serial correlation. It is hard to see why the parameters of equation 1 should be constant across countries while the "nuisance" serial correlation parameters should vary from country to country. As a practical matter, it is also difficult to estimate a serial correlation when we have so few time points; the estimates of country-specific serial correlations with the AGL data are very unstable.

Once we assume a single serial correlation process, it is easy to test whether the errors show serial correlation. A Lagrange multiplier test of the hypothesis that this single serial correlation is zero cannot be rejected at any conventional significance level; moreover, the estimated serial correlation is substantively small. ${ }^{6}$

In the presence of lagged dependent variables, OLS is consistent if the errors are temporally independent. Thus we no longer need to use the instrumental variable technique used by AGL. However, OLS will still be inefficient in the presence of contem- poraneously correlated errors and heteroscedasticity. ${ }^{7}$ AGL dealt with this via FGLS, which is the cause of the incorrect standard errors. We instead include a dummy variable to mark each year (save one). This picks up anything special about the economy in, say, 1973, and accounts for the bulk of country-pairspecific error correlation. However, this method does not account for all country-pair-specific correlation, since there may be special ties between, say, Germany and Austria, that go beyond the general year effect.

The OLS standard errors will be inconsistent in the presence of country-specific heteroscedasticity or country-pair-specific contemporaneous correlation of the errors. Analysis shows that both these phenomena persist in the data, although not very strongly. An obvious solution would be to create countryspecific dummy variables, but this is not possible here because LORG does not vary across time.

We thus calculate consistently estimated ("robust") standard errors, as well as the more usual OLS estimates of the standard errors, for equation 1. These robust standard errors are estimated using the general method suggested in White (1984). ${ }^{8}$ This method does not change the coefficient estimates but does improve estimation of standard errors. If $\mathbf{X}$ is the data matrix, the robust variance-covariance matrix of the errors is estimated by

$$
\left(\mathbf{X}^{\prime} \mathbf{X}\right)^{-1} \mathbf{X}^{\prime} \frac{\left(\mathbf{E}^{\prime} \mathbf{E}\right)}{T} \otimes \mathbf{I}_{\mathbf{T}} \mathbf{X}\left(\mathbf{X}^{\prime} \mathbf{X}\right)^{-1}
$$

The results of the reanalysis can be found in Table 1. Using either the OLS or robust standard errors, we see that AGL's substantive finding on the interactive effect of labor and left government on economic growth holds. The interactive coefficient in equation $1, \beta_{3}$, is positive and about four times its estimated standard error, while the estimates of $\beta_{1}$ and $\beta_{2}$ are both negative and between two and three times their estimated standard errors. Left government alone or an encompassing labor movement alone hurt economic growth, but in combination, they clearly enhance economic growth. However, AGL's results for unemployment and inflation do not fare as well. The interaction terms have the predicted signs, but neither is close to being statistically significant. Since the rate of economic growth is probably the best single indicator of national well-being and since economic growth was the source of the controversy engendered by Lange and Garrett (1985), it is thus most important for the conclusions of AGL that their result for economic growth holds.

There is little difference between the OLS and robust standard errors in Table 1 . This is an indication that the AGL data do not show much contemporaneous correlation of the errors once the yearly dummy variables are introduced. With large samples, it is likely that the robust standard errors will never be inferior to OLS standard errors, and with severe contemporaneous correlation, the robust standard errors are more accurate than the OLS standard 


\section{TABLE 1}

\section{Ordinary Least Squares Estimates for} Pooled Model

\begin{tabular}{|c|c|c|c|}
\hline $\begin{array}{l}\text { INDEPENDENT } \\
\text { VARIABLE }^{a}\end{array}$ & GROWTH & $\begin{array}{l}\text { INFLA- } \\
\text { TION }^{b}\end{array}$ & $\begin{array}{l}\text { UNEMPLOY- } \\
\text { MENT }^{b}\end{array}$ \\
\hline $\begin{array}{l}\text { Constant } \\
\mathrm{SE}^{c} \\
\text { robust } \mathrm{SE}^{d}\end{array}$ & $\begin{array}{l}4.65 \\
(.66) \\
(.65)\end{array}$ & $\begin{array}{l}.32 \\
(.66) \\
(.35)\end{array}$ & $\begin{array}{l}.38 \\
(.23) \\
(.11)\end{array}$ \\
\hline $\begin{array}{l}\text { Dep. var. (lagged) } \\
\text { SE } \\
\text { robust SE }\end{array}$ & $\begin{array}{l}.077 \\
(.066) \\
(.094)\end{array}$ & $\begin{array}{r}-.136 \\
(.068) \\
(.111)\end{array}$ & $\begin{array}{l}.301 \\
(.070) \\
(.11)\end{array}$ \\
\hline $\begin{array}{l}\text { Vulnerability to } \\
\text { OECD demand } \\
\text { SE } \\
\text { robust SE }\end{array}$ & $\begin{array}{r}-.0025 \\
(.0018) \\
(.0019)\end{array}$ & $\begin{array}{l}.001 \\
(.002) \\
(.002)\end{array}$ & $\begin{array}{l}.001 \\
(.0008) \\
(.001)\end{array}$ \\
\hline $\begin{array}{l}\text { OECD export } \\
\text { prod. } \\
\text { SE } \\
\text { robust SE }\end{array}$ & $\begin{array}{l}.002 \\
(.0011) \\
(.0012)\end{array}$ & $\begin{array}{c}-.004 \\
(.001) \\
(.001)\end{array}$ & $\begin{array}{l}.0005 \\
(.0004) \\
(.0004)\end{array}$ \\
\hline $\begin{array}{l}\text { OECD import } \\
\text { prod. } \\
\text { SE } \\
\text { robust SE }\end{array}$ & $\begin{array}{r}-.0009 \\
(.0016) \\
(.0017)\end{array}$ & $\begin{array}{l}.003 \\
(.004) \\
(.004)\end{array}$ & $\begin{array}{l}-.002 \\
(.001) \\
(.001)\end{array}$ \\
\hline $\begin{array}{l}\text { Labor organization } \\
\text { SE } \\
\text { robust SE }\end{array}$ & $\begin{array}{c}-.700 \\
(.216) \\
(.280)\end{array}$ & $\begin{array}{l}.051 \\
(.156) \\
(.143)\end{array}$ & $\begin{array}{l}-.019 \\
(.05) \\
(.046)\end{array}$ \\
\hline $\begin{array}{l}\text { Left cabinet } \\
\text { SE } \\
\text { robust SE }\end{array}$ & $\begin{array}{c}-.023 \\
(.009) \\
(.007)\end{array}$ & $\begin{array}{l}.012 \\
(.023) \\
(.023)\end{array}$ & $\begin{array}{l}.0005 \\
(.0004) \\
(.007)\end{array}$ \\
\hline $\begin{array}{l}\text { Interaction } \\
\text { SE } \\
\text { robust SE }\end{array}$ & $\begin{array}{l}.012 \\
(.003) \\
(.003)\end{array}$ & $\begin{array}{r}-.010 \\
(.009) \\
(.008)\end{array}$ & $\begin{array}{l}-.0007 \\
(.0029) \\
(.003)\end{array}$ \\
\hline
\end{tabular}

Source: Data on 16 OECD nations, 1971-84 from Alvarez, Garrett, and Lange (1991)

Note: Main entries are unstandardized OLS coefficient estimates. Estimates are computed with RATS 4.02 .

${ }^{a}$ Regressions include a series of yearly dummy variables, not shown.

${ }^{b}$ All variables are in first differences.

'OLS standard errors.

${ }^{d}$ Robust standard errors, based on White (1984).

errors. Since the robust standard errors are easy to compute and cross-national panel studies usually have large sample sizes, we would recommend that cross-national panel analysts who use OLS also compute robust standard errors.

Finally, we would like to emphasize that the problems with the AGL methodology cannot be avoided by simply adding a few extra observations per cross section. Most cross-national panel studies do have more time points than countries; accordingly, they may be estimated by FGLS. But the use of FGLS may lead to severe underestimates of standard errors in many cross-national panel studies, which leads us to recommend that analysts consider OLS with robust standard errors unless $\mathrm{T}$ is much greater than $\mathrm{N}$.

If $\mathrm{T}$ is slightly larger than $\mathrm{N}$, the estimated $\hat{\mathbf{\Omega}}$ matrix is no longer singular but contains about half as many $\left(N(N-1) / 2 \approx N^{2} / 2\right)$ parameters as there are observations $\left(N T \approx N^{2}\right.$ ). FGLS works because, asymptotically, OLS residuals give us a good estimate of $\boldsymbol{\Omega}$.
With only about two observations per parameter, we cannot have any assurance that the estimated $\hat{\boldsymbol{\Omega}}$ has any relationship to $\boldsymbol{\Omega}$. The Parks procedure will reliably estimate the standard errors of the model only when $\mathrm{T}$ is much larger than $\mathrm{N}$.

Freedman and Peters (1984) have shown that FGLS must underestimate the true standard errors. Two of us (Beck and Katz 1993) have undertaken a Monte Carlo analysis of the properties of FGLS and OLS (with robust errors) for typical cross-national panel data situations. These show that the FGLS underestimate of standard errors may be severe, and the efficiency gain slight, for typical cross-national panel situations.

In particular, "95\% confidence intervals" computed using FGLS contain the true parameter value only about half the time when $\mathrm{N}=18$ and $\mathrm{T}=22$; this increases to only about three times in four when $\mathrm{N}=$ 15 and $\mathrm{T}=28$ and is still below $90 \%$ when $\mathrm{N}=15$ and $\mathrm{T}=40$. In the first case, FGLS estimates of standard errors are only about a third of their true (simulated) sampling variation; when $N=15$ and $T=28$, estimated FGLS standard errors are still only $60 \%$ of simulated variability; even when $\mathrm{N}=15$ and $\mathrm{T}=40$, the FGLS standard errors are still only about $80 \%$ of the simulated variability. Since cross-national panel studies typically have Ns and Ts in this range, these Monte Carlo results indicate that the Parks method (FGLS) may not be ideal for this type of data.

The OLS standard errors, on the other hand, are good indicators of parameter sampling variation even in the presence of extreme contemporaneous correlation of the errors. In the worst case, the OLS standard errors overestimate sampling variability by under $20 \%$; for moderate amounts of contemporaneous correlation, the OLS standard errors approximate sampling variability well. In any event, the robust standard errors invariably do a good job at estimating the variability of the OLS estimates.

The Monte Carlo study also shows that FGLS is more efficient than OLS only when there is a high level of contemporaneous correlation of the errors. But even in the worst case for OLS, it is $80 \%$ as efficient as FGLS. For moderately correlated errors, OLS is just as efficient as FGLS; and OLS is more efficient than FGLS when the errors show little contemporaneous correlation.

In short, when the number of observations per cross section is less than the number of cross sections, FGLS cannot be used. Also, unless the number of observations per cross section greatly outweighs the number of cross sections, FGLS does a poor job of estimating the uncertainty in the model coefficients. The Monte Carlo results suggest that the method used here, OLS with robust standard errors, performs well. Thus we can trust our main positive finding that economic growth is enhanced by a fit between labor organization and political arrangements. The Monte Carlo study also indicates that the method used to obtain this finding is not simply a bad compromise in the presence of limited data but, 
rather, a method that should perform well for much cross-national panel data.

\section{Notes}

We would like to thank Gary King (for his persistence) and Brian Sala. Katz's work was supported by a National Science Foundation Graduate Fellowship.

1. We used an unsupported procedure, TSCREG, in SAS Version 5.18 (SAS Institute Inc. 1986). TCSREG produced, without warning, estimates of standard errors that are merely artifacts of rounding error. The SAS routine should not have computed any estimates, given our data set. Other programs that estimate similar models, such as SHAZAM (White, et al. 1990), correctly stop in the presence of insufficient data.

2. First differences instead of levels were used by AGL to deal with possible nonstationarity of the unemployment and inflation series.

3. All variables are as defined by AGL.

4. The reanalysis uses the sample period $1971-84$ because of the use of a lagged dependent variable. This change has no consequence for either the statistical argument or the substantive findings.

5. The rank of $\mathbf{E}^{\prime} \mathbf{E}$ is the rank of $\mathbf{E}$. If $T<N$, the rank of $\mathbf{E}$ is $T$; but $E^{\prime} E$ has $N$ rows and columns, so it must be singular.

6. The Lagrange multiplier test takes into account the panel structure of the data. For economic growth, the test statistic is .44. Since, under the null hypothesis, the Lagrange multiplier statistic has a chi-squared distribution with one degree of freedom, we clearly cannot reject the hypothesis that the errors are not serially correlated. The estimated serial correlation is under .12, with a standard error above .07.

7. Heteroscedasticity is not a serious problem in the AGL data because their dependent variables were growth rates and changes inflation and unemployment.

8. We have not found in the literature any applications of the White procedure to panel studies, but the generalization seems clear and the conditions for White's procedure to provide consistent estimates hold quite easily. The White procedure has only an asymptotic justification, but our large sample size (224) allows us to use asymptotic results with some confidence. The robust errors reported here correct only for contemporaneous error correlation and heteroscedasticity, because our data show no serial correlation. The White method can be extended to handle serially correlated errors.

9. The Monte Carlo results reported here are based on the experiments reported in Beck and Katz (1993). Details on all the experiments, as well as GAUSs code, are available from Beck. The results reported here deal only with problems caused by contemporaneously correlated errors.

\section{References}

$\rightarrow$ Alvarez, R. Michael, Geoffrey Garrett, and Peter Lange. 1991 "Government Partisanship, Labor Organization, and Macroeconomic Performance." American Political Science Review 85:539-56.

Beck, Nathaniel, and Jonathan N. Katz. 1992. "Model Assessment via Cross Validation." Presented at the annual meeting of the American Political Science Association, Chicago.

Beck, Nathaniel, and Jonathan N. Katz. 1993. "Panel Methods for Cross-national Data." Presented at the annual meeting of the Midwest Political Science Association, Chicago.

$\rightarrow$ Blais, André, Donald Blake, and Stéphane Dion. 1993. "Do Parties Make a Difference? Parties and the Size of Government in Liberal Democracies." American Journal of Political Science 37:40-62.

$\rightarrow$ Freedman, David, and Stephen Peters. 1984. "Bootstrapping a Regression Equation: Some Empirical Results." Journal of the American Statistical Association 79:97-106.

$\rightarrow$ Hicks, Alexander, and Duane Swank. 1992. "Politics, Institutions, and Welfare Spending in Industrialized Democracies, 1960-1982." American Political Science Review 86:658-74.

Kmenta, Jan. 1986. Elements of Econometrics. 2d ed. New York: Macmillan.

$\rightarrow$ Lange, Peter, and Geoffrey Garrett. 1985. "The Politics of Growth: Strategic Interaction and Economic Performance in the Advanced Industrial Democracies, 1974-1980." Journal of Politics 47:792-827.

$\rightarrow$ Parks, Richard W. 1967. "Efficient Estimation of a System of Regression Equations When Disturbances Are Both Serially and Contemporaneously Correlated." Journal of the American Statistical Association 62:500-509.

SAS Institute. 1986. SUGI Supplemental Library User's Guide, Version 5 Edition. Cary, NC: SAS Institute.

$\rightarrow$ Swank, Duane. 1992. "Politics and the Structural Dependence of the State in Democratic Capitalist Nations." American Political Science Review 86:38-54.

White, Halbert. 1984. Asymptotic Theory for Econometricians. Orlando: Academic.

White, Kenneth, S. Wong, D. Whistler, and S. Haun. 1990. Shazam User's Reference Manual Version 6.2. New York: McGraw-Hill.

Nathaniel Beck is Professor of and Jonathan N. Katz is Doctoral Candidate in Political Science, University of California at San Diego, La Jolla, CA 92093.

R. Michael Alvarez is Assistant Professor of Political Science, California Institute of Technology, Pasadena, CA 91125.

Geoffrey Garrett is Assistant Professor of Political Science, Stanford University, Stanford, CA 94305.

Peter Lange is Professor of Political Science, Duke University, Durham, NC 27706. 